\title{
The BRCA2 mutation status shapes the immune phenotype of prostate cancer
}

\author{
Maximilian Jenzer ${ }^{1,2} \cdot$ Peter Ke $\beta^{1} \cdot$ Cathleen Nientiedt ${ }^{1,2} \cdot$ Volker Endris $^{3} \cdot$ Maximilian Kippenberger $^{1}$. \\ Jonas Leichsenring ${ }^{3}$. Fabian Stögbauer ${ }^{3}$. Josh Haimes ${ }^{4}$. Skyler Mishkin ${ }^{4}$. Brian Kudlow ${ }^{4}$. Adam Kaczorowski ${ }^{1}$. \\ Stefanie Zschäbitz ${ }^{1,2}$. Anna-Lena Volckmar ${ }^{3} \cdot$ Holger Sültmann ${ }^{5,6}$. Dirk Jäger ${ }^{2}$. Anette Duensing ${ }^{7,8,9,10}$. \\ Peter Schirmacher ${ }^{3} \cdot$ Markus Hohenfellner $^{10}$. Carsten Grüllich ${ }^{2,11} \cdot$ Albrecht Stenzinger $^{3} \cdot$ Stefan Duensing ${ }^{1,10}$
}

Received: 30 October 2018 / Accepted: 5 September 2019 / Published online: 23 September 2019

(c) The Author(s) 2019

\begin{abstract}
Defects in DNA damage repair caused by mutations in $B R C A 1 / 2$, ATM or other genes have been shown to play an important role in the development and progression of prostate cancer. The influence of such mutations on anti-tumor immunity in prostate cancer, however, is largely unknown. To better understand the correlation between $B R C A 1 / 2$ mutations and the immune phenotype in prostate cancer, we characterized the immune infiltrate of eight $B R C A 2$-mutated tumors in comparison with eight $B R C A 1 / 2$ wild-type patients by T-cell receptor sequencing and immunohistochemistry for CD45, CD4, CD8, FOXP3, and CD163. In addition, we analyzed seven prostate cancer biopsies that were either BRCA2 or ATM-mutated in comparison with wild-type tumors. Whereas in $B R C A 1 / 2$ wild-type tumors, immune cells were found predominantly extratumorally, most $B R C A 2$-mutated tumors including one biopsy showed a significantly increased intratumoral immune cell infiltration. The ratio of intratumoral to extratumoral immune cells was considerably higher in BRCA2-mutated tumors for all markers and reached statistical significance for CD4 $(p=0.007), \operatorname{CD} 8(p=0.006)$, and FOXP3 $(p=0.001)$. However, the intratumoral CD8 to FOXP3 ratio showed a trend to be lower in BRCA2-mutated tumors suggesting a more suppressed tumor immune microenvironment. Our findings provide a rationale for the future use of immune oncological approaches in BRCA2-mutated prostate cancer and may encourage efforts to target immunosuppressive T-cell populations to prime tumors for immunotherapy.
\end{abstract}

Keywords Prostate cancer $\cdot$ Homologous recombination deficiency $\cdot B R C A 1 / 2 \cdot$ Tumor-infiltrating lymphocytes $\cdot$ Tumor microenvironment $\cdot$ Immune checkpoint inhibitors

\section{Abbreviations}

CNA Copy number alterations

FFPE Formalin-fixed, paraffin-embedded

Maximilian Jenzer and Peter Keß are co-first authors.

Markus Hohenfellner, Carsten Grüllich, Albrecht Stenzinger, and Stefan Duensing jointly supervised this work.

Electronic supplementary material The online version of this article (https://doi.org/10.1007/s00262-019-02393-x) contains supplementary material, which is available to authorized users.

Albrecht Stenzinger

albrecht.stenzinger@med.uni-heidelberg.de

Stefan Duensing

stefan.duensing@med.uni-heidelberg.de

Extended author information available on the last page of the article

$\begin{array}{ll}\text { HPF } & \text { High-power field } \\ \text { HR } & \text { Homologous recombination } \\ \text { IHC } & \text { Immunohistochemistry } \\ \text { mCRPC } & \text { Metastatic castration-resistant prostate cancer } \\ \text { MDSC } & \text { Myeloid-derived suppressor cell } \\ \text { NGS } & \text { Next-generation sequencing } \\ \text { ORR } & \text { Objective response rate } \\ \text { OS } & \text { Overall survival } \\ \text { PARP } & \text { Poly-(ADP-ribose) polymerase } \\ \text { PFS } & \text { Progression-free survival } \\ \text { TCR } & \text { T-cell receptor } \\ \text { TIL } & \text { Tumor-infiltrating lymphocyte }\end{array}$




\section{Introduction}

Prostate cancer is the most common non-cutaneous cancer in men and the second leading cause of death from cancer in men in the USA and worldwide [1, 2]. Defects in DNA damage repair are increasingly recognized to define a subgroup of prostate cancer patients with more aggressive tumor growth and earlier onset of disease [3]. BRCAl and $B R C A 2$ are two genes involved in homologous recombination (HR)-mediated repair of DNA double strand breaks and have first been described as tumor suppressor genes in hereditary breast cancer $[4,5]$. HR deficiency caused by hereditary and/or somatic mutations in $B R C A 1 / 2$ or other DNA repair genes have been found not only in breast cancer but also in other types of cancer including ovarian or prostate cancer [3]. Mutations in $B R C A 1 / 2$ lead to an increase of the somatic mutation rate [6-8], indels, and chromosome copy number alterations (CNAs) [9] and, therefore, possibly promote the formation of neoepitopes [10]. BRCA1/2-deficient prostate cancers not only show increased sensitivity to platinum-based chemotherapies [11], but also to poly-(ADP-ribose) polymerase (PARP) inhibitors [12-14], thus giving BRCA1/2 deficiency a high clinical relevance in these patients $[15,16]$.

Immune checkpoint inhibitors targeting CTLA-4 or PD-1/PD-L1 are increasingly used therapeutically in a number of tumor entities including renal cell carcinoma and bladder cancer [17]. Biomarkers predicting the response to immune checkpoint inhibitors include PD-L1 status [18], mutational load [7], and neoepitope formation [19] among others. Prostate cancer is known to have a relatively low mutational load in comparison with other epithelial malignancies $[20,21]$. In line with this finding, the median progression-free survival (PFS) in a phase III trial using the anti-CTLA-4 antibody ipilimumab in asymptomatic or minimally symptomatic metastatic castration-resistant prostate cancer (mCRPC) patients was only 5.6 months in the treatment arm vs. 3.8 months in the placebo arm with no difference in the median overall survival (OS, 28.7 vs. 29.7 months) [22]. In another phase III trial, ipilimumab was compared to placebo in $\mathrm{mCRPC}$ patients who progressed after docetaxel and had received radiotherapy for bone metastases with no difference in the median OS (11.2 vs. 10.0 months) [23]. While a phase I study with the anti-PD-1 antibody nivolumab showed no response in $13 \mathrm{mCRPC}$ patients [24], preliminary data from a phase II trial of the anti-PD-1 antibody pembrolizumab in 258 patients with docetaxel-refractory mCRPC showed a $5 \%$ objective response rate (ORR) regardless of PD-L1 status, but an ORR of $12 \%$ in patients with somatic BRCA1/2 or ATM mutations [25]. The latter finding is in line with results, showing that BRCA2 mutations are enriched in melanoma patients responding to antiPD-1 therapy [26]. Since HR deficiency causes increased mutational load thereby potentially creating neoepitopes, it could be used to define a subgroup of prostate cancer patients who would potentially benefit from immune checkpoint inhibitors.

A number of studies have reported that the infiltration with CD4- or CD8-positive lymphocytes is increased in prostate cancer compared to benign prostate tissue [27]. However, other reports did not find such an association [28]. T-cell infiltration has been reported to increase with androgen deprivation [29, 30], but almost nothing is known about the immune milieu in mCRPC [31]. In contrast to most other cancers, a high number of CD8-positive TILs in prostate cancer appear to be associated with a poor prognosis including a shorter time to biochemical and clinical progression, castration resistance, and/or metastatic dissemination [32, 33]. Similar results have been reported for a high numbers of CD4-positive TILs [34, 35]. The reason for this observation may be a dysfunction or a suppression of T cells, e.g., through PD-L1 [33] or CD73 [36]. In addition, immunosuppressive cells such as FOXP3-positive regulatory T cells and CD163-positive tumor-associated (M2) macrophages were also found to be enriched in prostate cancer and associated with a more unfavorable patient outcome [28, 37].

It has previously been shown in breast cancer that HR deficiency caused by BRCAl inactivation is accompanied by an increase of tumor infiltration with CD4-positive T cells, CD8-positive cytotoxic T cells, PD-L1 expression, and possibly response to immune checkpoint inhibition [10, 38, 39]. Remarkably, a higher abundance of TILs was not found in BRCA2-mutated breast cancer, despite similar genomic alterations, suggesting that additional mechanisms than the mutational burden may shape cellular immune responses [39]. A relative deficiency in TILs was also detected in BRCA2mutated ovarian cancer when compared to BRCA1-mutated tumors [40]. However, other studies found increased numbers of CD3- and CD8-positive TILs in BRCA1/2-mutated ovarian cancer without significant difference between BRCA1 or BRCA2 mutations [10]. The impact of BRCA1/2 mutations on the cellular immune phenotype of prostate cancer is largely unknown.

To better understand the impact of $B R C A 1 / 2$ mutations on the immune phenotype of prostate cancer, we initiated a proof-of-concept study to characterize the cellular immune infiltrate of eight BRCA2 mutated in comparison with eight $B R C A 1 / 2$ wild-type prostate cancer patients by T-cell receptor (TCR)-sequencing and immunohistochemistry (IHC) for CD45, CD4, CD8, FOXP3, and CD163. In addition, we characterized the immune infiltrate in seven prostate cancer biopsies that were either BRCA2 or ATM mutated or wild type. Results show an increased number of tumor-infiltrating lymphocytes, including potentially immunosuppressive 
FOXP3-positive lymphocytes, in BRCA2-mutated prostate cancers compared to the $B R C A 1 / 2$ wild-type group, which harbored mostly extratumoral immune cells. Our findings provide a rationale for the future use of immune oncological agents in BRCA2-mutated prostate cancer patients and may encourage efforts to target immunosuppressive T-cell populations.

\section{Methods}

\section{Patient samples and targeted next-generation sequencing (NGS)}

In this retrospective proof-of-concept study, formalin-fixed, paraffin-embedded (FFPE) tissue sections from 16 men with prostate adenocarcinoma and known $B R C A 1$ and $B R C A 2$ mutation status were analyzed. Eight patients were $B R C A 2$ mutated, and one patient had a confirmed germline mutation. The other eight patients were a control group matched for age, Gleason Score, initial PSA, and initial TNM-state, but were $B R C A 2$ wild type. All 16 patients were $B R C A 1$ wild type. The mutation status of $B R C A 1$ and $B R C A 2$ was determined by targeted next generations sequencing of tumor tissue as previously reported [16]. In addition, FFPE prostate biopsy samples from seven patients were analyzed after mutation testing by targeted NGS using a panel of 37 DNA damage repair and checkpoint genes (ATM, ATR, BARDI, BRCA1, BRCA2, BRIP1, CHEK1, CHEK2, FAM175A, FANCA, FANCB, FANCC, FANCD2, FANCE, FANCF, FANCG, FANCI, FANCL, FANCM, ERCC2, ERCC4, ERCC5, MLH1, MSH2, MSH6, PALB2, PMS1, PMS2, RAD50, RAD51C, RAD51D, RECQL4, MRE11A, NBN, $S L X 4, T P 53, X R C C 2)$. Amplicon library preparation was performed with the Ion AmpliSeq Library Kit v2.0 (Thermo Fisher Scientific, Waltham, MA, USA) [41]. After the PCR reaction, primer end sequences were partially digested using FuPa reagent, followed by the ligation of barcoded sequencing adapters (Ion Xpress Barcode Adapters, Life Technologies). The final libraries were diluted to a concentration of $50 \mathrm{pM}$ and processed on Ion Chef (Thermo Fisher Scientific). Sequencing was performed on an Ion S5XL/Prime sequenzer using 520/530 chips with a mean coverage per amplicon between 1000 and 3000 fold. Data analysis, variant calling, and annotation were performed as previously described [42-44]. All patients included in the analysis were of Caucasian descent.

\section{T-cell receptor (TCR)-sequencing}

RNA from the aforementioned FFPE tissue samples was extracted with the Maxwell RSC RNA FFPE Kit (Promega, Madison, WI, USA) according to the manufacturer's protocol with the exception that the DNase step was omitted. RNA was quantified with Qubit RNA HS Assay Kit (Thermo Fisher Scientific, Waltham, MA, USA) after purification. Between 786 to $1000 \mathrm{ng}$ of RNA was used as input for library generation with the Archer Immunoverse ${ }^{\mathrm{TM}}$-HS TCR beta/gamma Kit, for Illumina (DB0232; ArcherDX, Boulder, CO, USA) following protocol revision LA092.A. All purifications during library preparation were performed with Agencourt AMPure XP (Beckman Coulter, Brea, CA, USA). Final libraries were quantified using the KAPA Library Quantification Kit (KAPA Biosystems, Wilmington, MA, USA) and pooled to equimolar concentration. The intended concentration of pooled libraries was confirmed with the KAPA Library Quantification Kit.

Libraries were sequenced on an Illumina NextSeq 500 using NextSeq 500 v2 reagents (Illumina, San Diego, CA, USA) for paired end, 150 base pair reads, and dual index reads. Libraries were multiplexed, such that an average of 1.86 million paired reads was attributed to each library. The flow cell was loaded with $1.6 \mathrm{pM}$ denatured library and $20 \%$ PhiX Control v3 (Illumina).

Data were analyzed by Archer Analysis version 5.1.3 (ArcherDX). Briefly, adapter sequences are trimmed from the reads, and then, PCR duplicates are collapsed using molecular barcodes to identify unique molecules. Consensus reads representing unique input molecules are passed to MiXCR for V-(D)-J segment mapping and clonotype assembly. When used alone, "clones" means the number of total identified clones, while "clonotypes" means the number of identified unique sequences.

\section{Immunohistochemistry}

Consecutive FFPE tissue sections were deparaffinized in xylene and rehydrated in a graded ethanol series. Antigen retrieval was performed with a steam cooker using retrieval buffer (Dako, Agilent, Santa Clara, CA, USA,). Primary antibodies used were directed against Ki-67 (MIB-1, Dako, 1:100), CD4 (4B12, NCL-L-CD4-368, Leica, Wetzlar, Germany, 1:50), CD8 (144B, ab17147, Abcam, Cambridge, UK, 1:25), CD45 (2B11 + PD7/26, Dako, 1:100), CD163 (10D6, NCL-L-CD163, Leica, 1:100), FOXP3 (236A/E7, ab20034, Abcam, 1:100), and PD-L1 (SP142, ab228472, Abcam, $1: 100$ ) and were incubated overnight at $4{ }^{\circ} \mathrm{C}$. All antibodies have previously been extensively validated [45-51]. Immunodetection was done with a biotinylated secondary goat anti-mouse $\operatorname{IgG}(\mathrm{H}+\mathrm{L})$ antibody (31800, Invitrogen, Thermo Fisher Scientific, 1:200), streptavidin conjugated to horseradish peroxidase (Thermo Fisher Scientific) and 3,3'-diaminobenzidine chromogen (Thermo Fisher Scientific). Nuclear counterstaining was done with hematoxylin (Thermo Fisher Scientific). 
For Ki-67, five representative $1430 \times 1070 \mu \mathrm{m}$ areas with more than $50 \%$ tumor cell content were photographed using a Leica DM5000 B microscope and the percentage of positive tumor cells was counted. For CD45, CD4, CD8, FOXP3, and CD163, three regions were defined: Intratumoral (IT), extratumoral with direct contact to the tumor $(\mathrm{ET} 1,<10 \mu \mathrm{m}$ distance from tumor), and extratumoral with one high-power field (HPF, $40 \times$ objective) distance (ET2, $500 \mu \mathrm{m}$ distance from tumor) to control for non-tumor-associated intraprostatic chronic inflammation. The microscopic fields for our analyses were chosen to represent TIL heterogeneity. For example, if $20 \%$ of the IT area showed a high density of TILs and the other $80 \%$ a low density, we analyzed five fields total of which one was representative of the high-density area and four of the low-density area. Positive cells in five HPFs were counted for each patient and each region. All cell counts were performed in a blinded fashion and the tumor mutation status was unblinded only after all counts were completed. One main observer performed the counts (P. Keß) and two independent observers (M. Jenzer and S. Duensing) performed additional counts on selected cases. Areas of acute inflammation and necrosis were excluded from the analyses.

\section{Statistical analysis}

For statistical analyses, Student's $t$ test for independent samples, Mann-Whitney $U$ test, or Fisher's exact test was used wherever applicable. Differences with a $p$ value of $\leq 0.05$ were considered statistically significant. All data are available from the corresponding author at reasonable request.

\section{Results}

\section{Enhanced intratumoral lymphocyte infiltration in BRCA2-mutated prostate cancers}

Eight BRCA2-mutated prostate cancer patients and eight $B R C A 1 / 2$ wild-type patients matched for age, Gleason score, initial PSA, and initial TNM state were selected for this retrospective analysis. All patients and mutations have previously been reported in an unrelated study (Supplementary Table 1) [16]. BRCA2-mutated patients showed a trend towards a shorter progression-free survival (PFS; 22 vs. 34.9 months, $p=0.32$ ) under androgen deprivation therapy and to shorter overall survival (OS, 43.3 vs. 58.5 months, $p=0.28$ ), but differences in these and all other clinico-pathological characteristics were not statistically significant (Supplementary Table 2).

We first sought to explore the diversity of the T-cell infiltrate and performed T-cell receptor sequencing of the 16 tumors. Results showed a wide range in the number of T-cell clones in both BRCA1/2 wild-type (median 20, range 3-124)

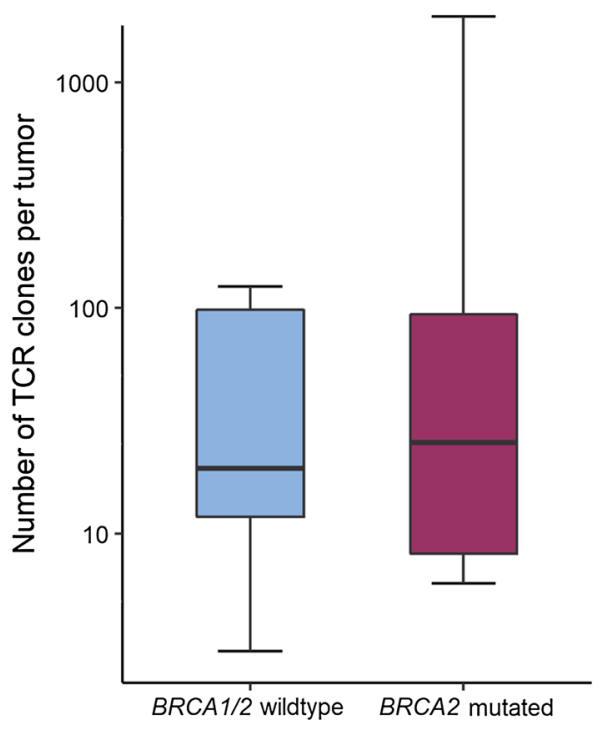

Fig. 1 Number of TCR clones per tumor by BRCA1/2 mutation status. Box plots represent the median number of identified TCR clones per sample in BRCA1/2 wild-type (blue) and BRCA2-mutated (red) prostate cancer identified by TCR sequencing. Whiskers representing minimum and maximum of each group. A $\log _{10}$ scale is used for the $y$-axis

and BRCA2-mutated (median 25.5, range 6-1954) tumors (Fig. 1). While the two tumors with the highest number of both total clones and unique clonotypes, respectively, were $B R C A 2$ mutated, there was overall no significant difference between BRCA2-mutated and BRCA1/2 wild-type tumors $(p=1.0)$. The clonality as a diversity measure normalized to the number of unique T-cell clones, ranging from 0 (absolute polyclonal) to 1 (absolute monoclonal), was also similar $(p=0.26)$ between BRCA1/2 wild-type (0.018) and BRCA2mutated (0.032) tumors.

Based on these results, we decided to perform a detailed in situ analysis of the immune cell composition in different compartments of the tumors. An immunostochemical analysis for CD45, CD4, CD8, FOXP3, and CD163 was performed (Figs. 2, 3). In addition, tumors were stained for Ki-67 as a marker for cell proliferation. Altogether, a total of $1280 \mathrm{HPFs}$ were analyzed in the 16 patients and in three distinct compartments: intratumoral (IT), extratumoral 1 (ET1), and extratumoral 2 (ET2), as illustrated in Fig. 2. Representative immunostainings in a BRCA2-mutated and a BRCA1/2 wild-type tumor, respectively, are shown in Fig. 3.

In BRCA1/2 wild-type tumors (Fig. 4a), significantly more CD8 positive cells (mean 23 vs. 9.7 per HPF, $p=0.001$ ) were detected in the ET1 compartment when compared to the IT compartment. There were also more CD4 positive cells (mean 21 vs. 13.4 per HPF, $p=0.10$ ), FOXP3 positive cells (mean 6.2 vs. 2.8 per HPF, $p=0.10$ ), CD45 positive cells (mean 44.3 vs. 29.1 per HPF, $p=0.17$ ), and CD163 positive cells (mean 19.8 vs. 17.2 per HPF, $p=0.59$ ) in the 

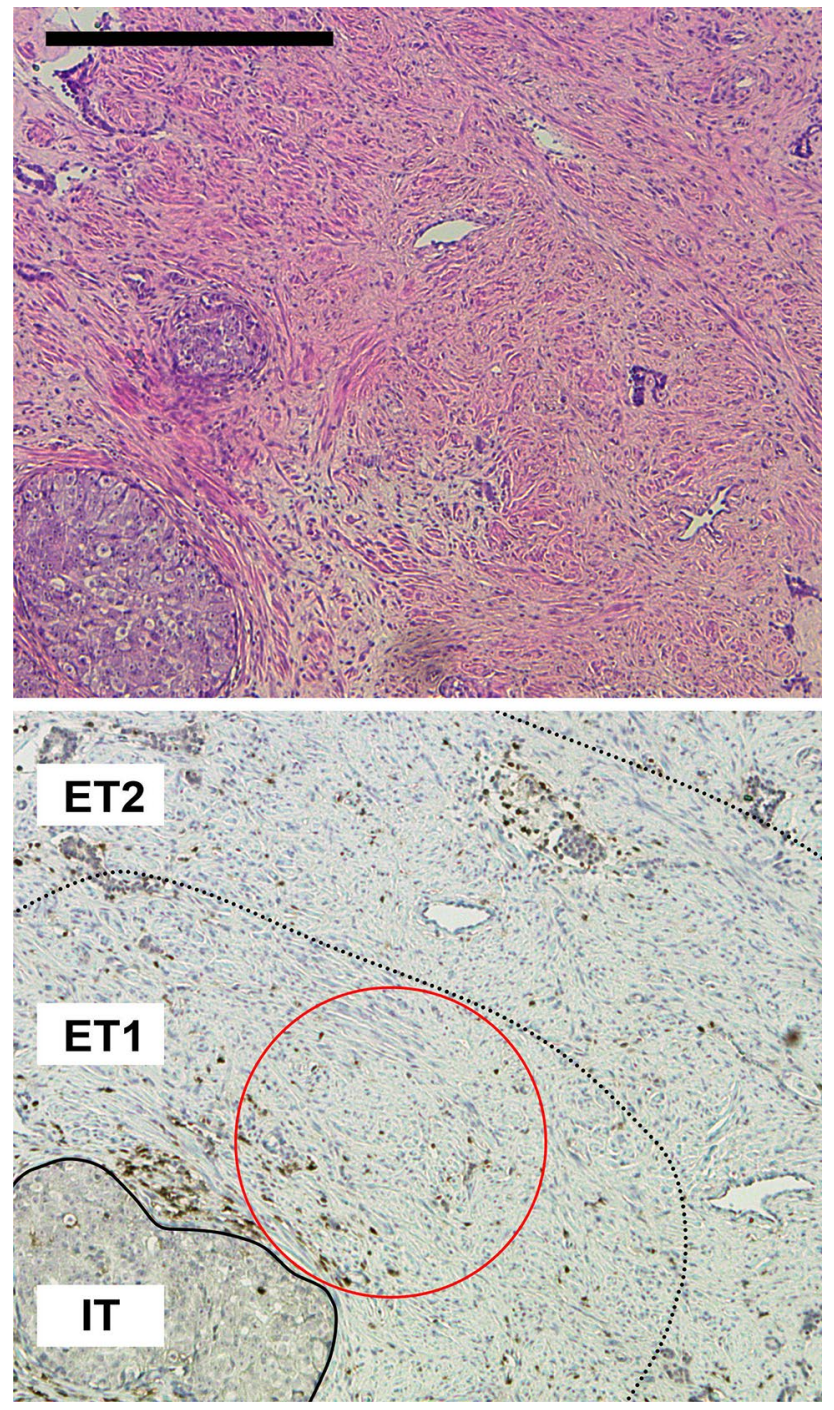

Fig. 2 Overview of tumor and microenvironmental compartments analyzed. Representative H\&E (top panel) and immunohistochemical (bottom panel) staining of prostate cancer for CD45 showing the three compartments intratumoral (IT), extratumoral 1 (ET1) and extratumoral 2 (ET2) used in this study. The red circle stands for a representative high-power field (40-fold objective, $500 \mu \mathrm{m}$ in diameter) in the ET1 compartment. The scale bar represents $500 \mu \mathrm{m}$

ET1 compartment than in the IT compartment, but differences did not reach statistical significance (Fig. 4a).

BRCA2-mutated tumors (Fig. 4b) harbored significantly more FOXP3 positive cells (mean 7.4 vs. 3.0 per HPF, $p=0.04$ ) intratumorally than in the ET1 compartment. A similar trend towards an enrichment of immune cells in the IT compartment was found for CD4 positive cells (mean 32.9 vs. 14.6 per HPF, $p=0.07$ ), CD45 positive cells (mean 46.3 vs. 24.6 per HPF, $p=0.16$ ), CD163 positive cells (mean 24.6 vs. 15.1 per $\mathrm{HPF}, p=0.2$ ), and CD8 positive cells (mean 20.1 vs. 12.4 per HPF, $p=0.24$ ) without reaching statistical significance (Fig. 4b).

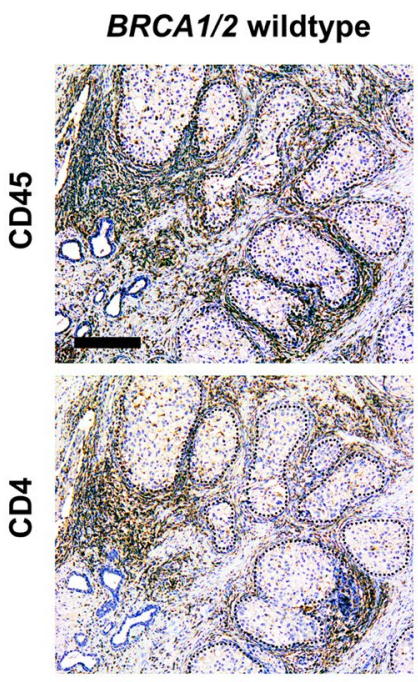

\section{BRCA2 mutated}
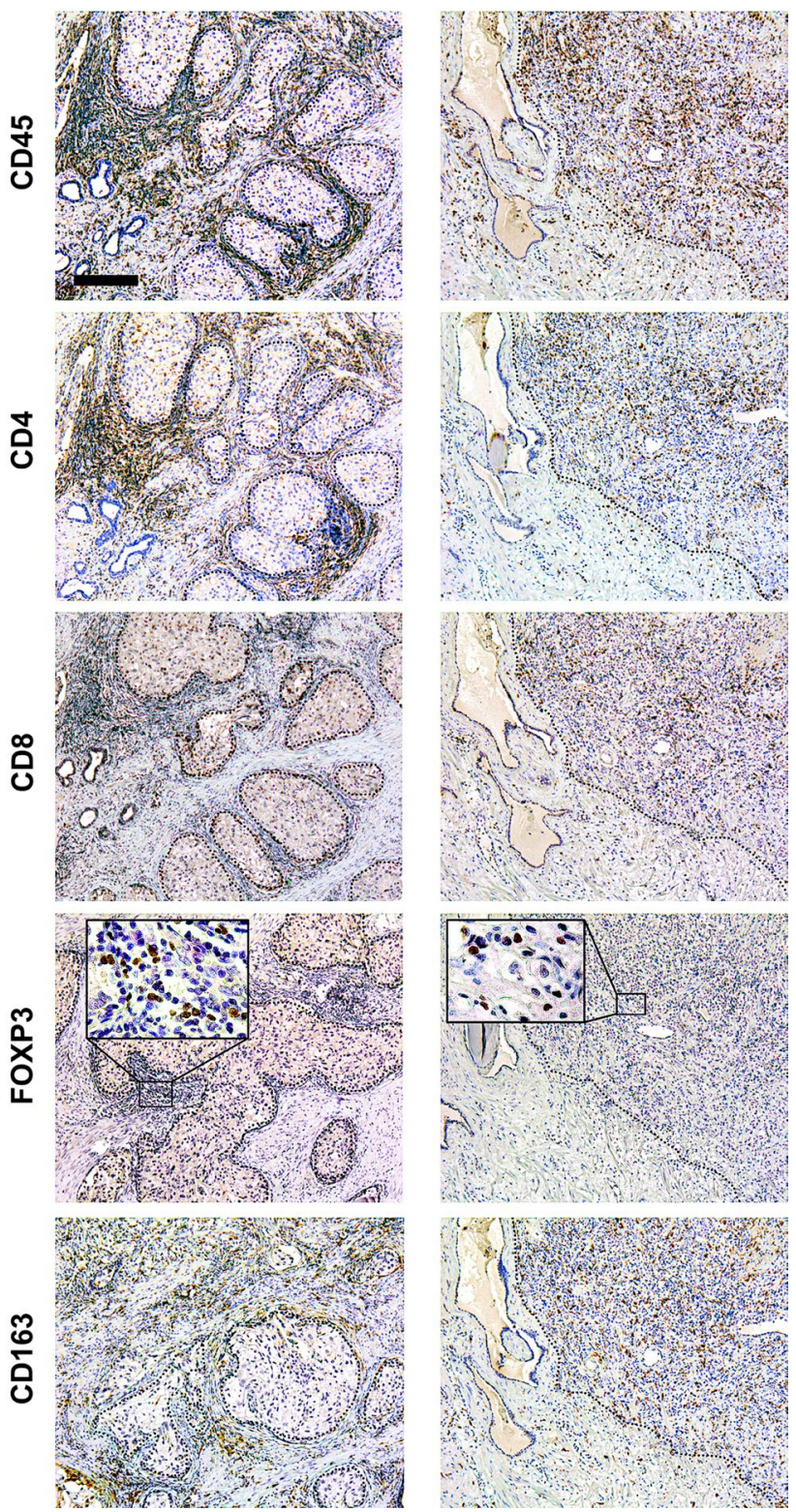

Fig. 3 Overview of immunohistochemical stainings. Representative immunohistochemical stainings for CD45 (pan-leucocyte), CD4 (T helper cells), CD8 (cytotoxic T cells), FOXP3 (regulatory $\mathrm{T}$ cells), and CD163 (macrophages) on consecutive slides of a BRCA1/2 wildtype and a $B R C A 2$-mutated prostate cancer. The dotted line represents the border between tumor and stroma. Scale bar represents $200 \mu \mathrm{m}$

We next compared the immune cell infiltration in the IT and ET1 compartments of both groups (Fig. 4c) and found that BRCA2-mutated tumors harbored significantly more CD4 positive cells (mean 32.9 vs. 13.4 per HPF, $p=0.02$ ) and FOXP3 positive cells (mean 7.4 vs. 2.8 per HPF, $p=0.03$ ) than BRCA1/2 wild-type tumors. BRCA2mutated tumors also showed a trend for more CD8 positive cells (mean 20.1 vs. 9.7 per HPF, $p=0.12$ ) that did not reach 
A

CD45

CD4

CD8

FOXP3

CD163
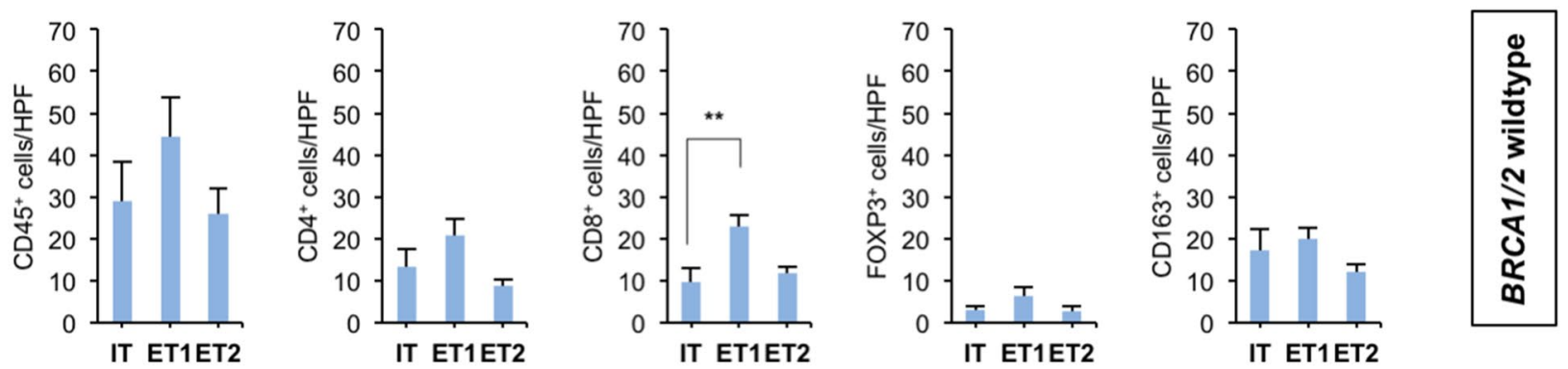

B
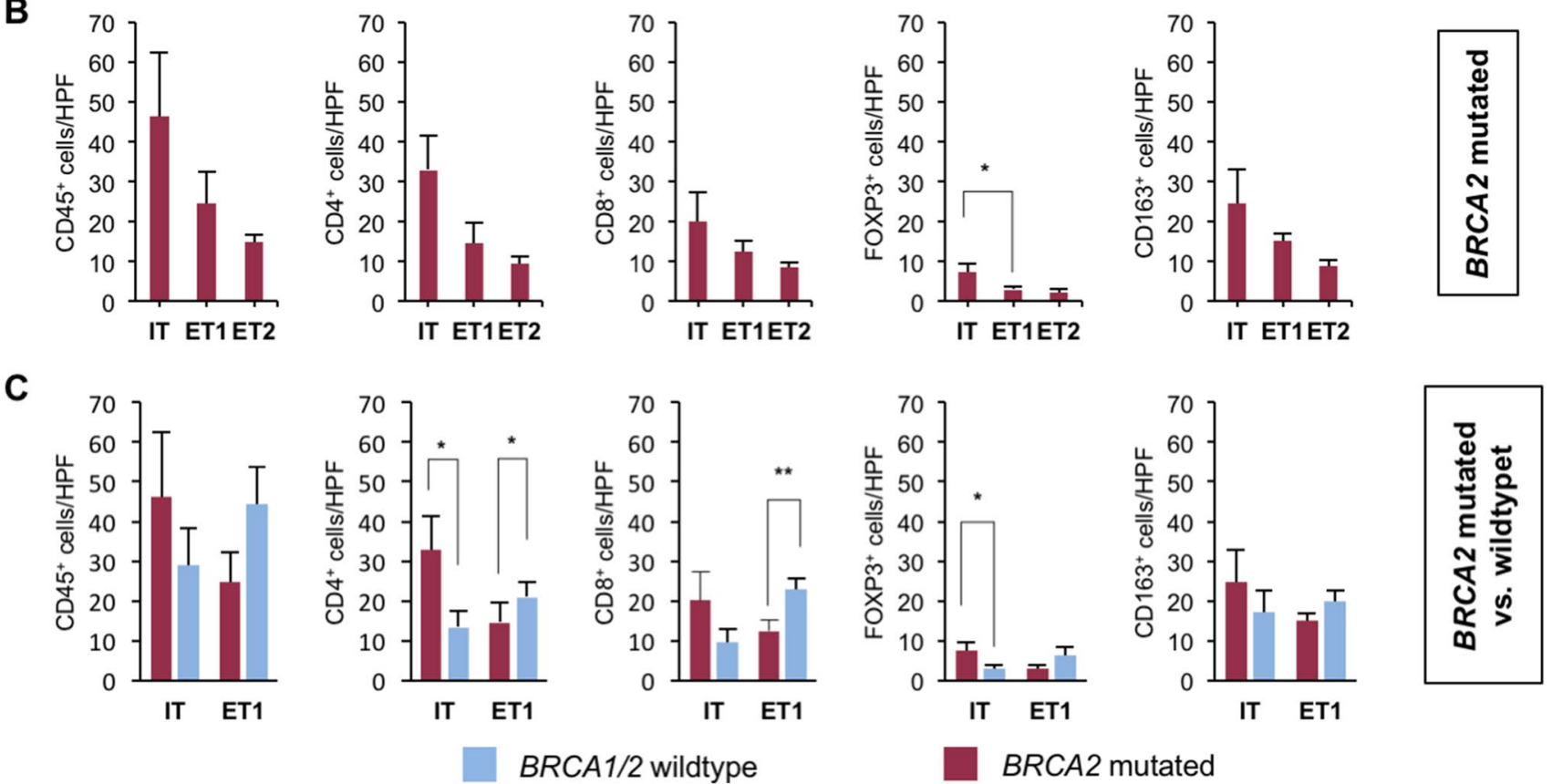

$B R C A 1 / 2$ wildtype

Fig. 4 BRCA2-mutated tumors harbor more intratumoral immune cells. a, b Bar graphs show the mean number of positive cells (+ standard error) per $40 \times \mathrm{HPF}$ in $B R C A 2$-mutated or BRCA1/2 wildtype prostate cancer in the intratumoral (IT), extratumoral 1 (ET1), and extratumoral 2 (ET2) compartments for CD45, CD4, CD8, FOXP3, and CD163. c Bar graphs show the mean number of positive cells (+ standard error) per $40 \times$ HPF in BRCA2-mutated compared

statistical significance. The number of CD45 positive cells (mean 46.3 vs. 29.1 per HPF, $p=0.27$ ) and CD163 positive cells (mean 24.6 vs. 17.2 per HPF, $p=0.36$ ) was also higher but differences were, again, not statistically significant (Fig. 4c).

In the ET1 compartment, BRCA1/2 wild-type tumors had significantly more CD8 positive cells (mean 23 vs. 12.4 per HPF, $p=0.004$ ) and CD4 positive cells (mean 21 vs. 14.6 per HPF, $p=0.04$ ) than BRCA2-mutated tumors. Furthermore, $B R C A 1 / 2$ wild-type tumors showed a trend towards more CD45 positive cells (mean 44.3 vs. 24.6 per HPF, $p=0.06$ ), more CD163 positive cells (mean 19.8 vs. 15.3 per HPF, $p=0.10$ ) and more FOXP3 positive cells (mean 6.2 vs. 3.0 per HPF, $p=0.11$ ) in the ET1 compartment (Fig. 4c). to BRCA1/2 wild-type prostate cancer in the intratumoral (IT) and extratumoral 1 (ET1) compartments for CD45, CD4, CD8, FOXP3, and CD163. Each bar represents the mean of five $40 \times$ HPF from the eight patients of each group i.e., BRCA1/2 wild type and $B R C A 2$ mutated. BRCA1/2 wild-type tumors in blue, BRCA2-mutated tumors in red. Standard errors are shown. $* p \leq 0.05$, $* * \leq 0.005$

In the more distant ET2 compartment, BRCA1/2 wildtype tumors showed a trend towards more CD45 positive cells (mean 25.9 vs. 14.9 per HPF, $p=0.05$ ) and CD8 positive cells (mean 11.6 vs. 8.4 per HPF, $p=0.07$ ) compared to $B R C A 2$-mutated tumors. Differences for cells positive for CD163 (mean 11.9 vs. 8.9 per HPF, $p=0.38$ ), FOXP3 (mean 2.7 vs. 2.2 per HPF, $p=0.56$ ) and CD4 (mean 9.5 vs. 8.7 per HPF, $p=0.64$ ) were not statistically significant (not shown).

$B R C A 2$-mutated and BRCA1/2 wild-type tumors showed no differences in the proliferation rate as determined by the percentage of Ki-67 positive tumor cells (mean 16.9 vs. $12.7 \%$ per HPF, $p=0.88$, Supplementary Figure 1).

In addition, we analyzed the presence and frequency of PD-L1 positive TILs in BRCA2-mutated and wild-type 
patients. The overall frequency of these cells was low and slightly higher in BRCA2-mutated tumors (mean $=0.6$ PD-L1 positive TILs per $40 \times \mathrm{HPF}$ ) in comparison with wild-type tumors (mean $=0.38$ per HPF) albeit without reaching statistical significance $(p=0.2)$.

Taken together, these results demonstrate that BRCA2mutated tumors contain an increased number of intratumoral immune cells when compared to BRCA1/2 wild-type tumors in particular CD4- and FOXP3-positive cells.

\section{Higher IT/ET1 ratio in BRCA2-mutated prostate cancers}

To further corroborate the notion that BRCA2-mutated tumors contain more intratumoral immune cells than $B R C A 1 / 2$ wild-type tumors, we calculated the ratio of intratumoral (IT) to directly extratumoral (ET1) positive cells for each staining and each patient (Fig. 5a-e). The mean IT/ET1 ratios were found to be significantly higher in
$B R C A 2$-mutated tumors than $B R C A 1 / 2$ wild-type tumors for CD4 (3.21 vs. 0.70, $p=0.007$ ), CD8 (2.98 vs. 0.42, $p=0.006)$ and FOXP3 (2.52 vs. $0.74, p=0.001)$ positive cells (Fig. 5f). For CD45 positive cells, the IT/ET1 ratio showed a trend to be higher in BRCA2-mutated tumors (2.95 vs. $0.92, p=0.08$ ) without reaching statistical significance, while for CD163 positive cells, the difference was not statistically significant (1.64 vs. $1.05, p=0.38$; Fig. 5 f).

These results underscore the differences in the distribution of immune cells between BRCA2-mutated and BRCA1/2 wild-type tumors in particular for the CD4-, CD8-, and FOXP3-positive lymphocytes.

\section{Lower intratumoral CD8/FOXP3 ratio in BRCA2-mutated tumors}

Since not only cytotoxic CD8 positive T lymphocytes but also potentially immunosuppressive FOXP3 positive regulatory $\mathrm{T}$ cells were found to be increased intratumorally in
Fig. 5 Shift in immune cell distribution in BRCA2-mutated tumors as reflected by the IT/ ET ratio. Bar graphs show the ratio of mean positive cell counts from five representative HPF each of the intratumoral (IT) and extratumoral closest to the tumor (ET1) compartment of each patient sorted from highest to lowest for CD45 (a), CD4 (b), CD8 (c), FOXP3 (d), and $\mathrm{CD} 163(\mathbf{e}) . \mathrm{A} \log _{10}$ scale is used for the $y$-axis. f Bar graph showing mean IT/ET1 ratio for all eight patients of each group for CD45, CD4, CD8, FOXP3, and $\mathrm{CD} 163$. BRCA1/2 wildtype tumors in blue, BRCA2mutated tumors in red. Standard errors are shown. ${ }^{*} p \leq 0.05$, $* * p \leq 0.005$
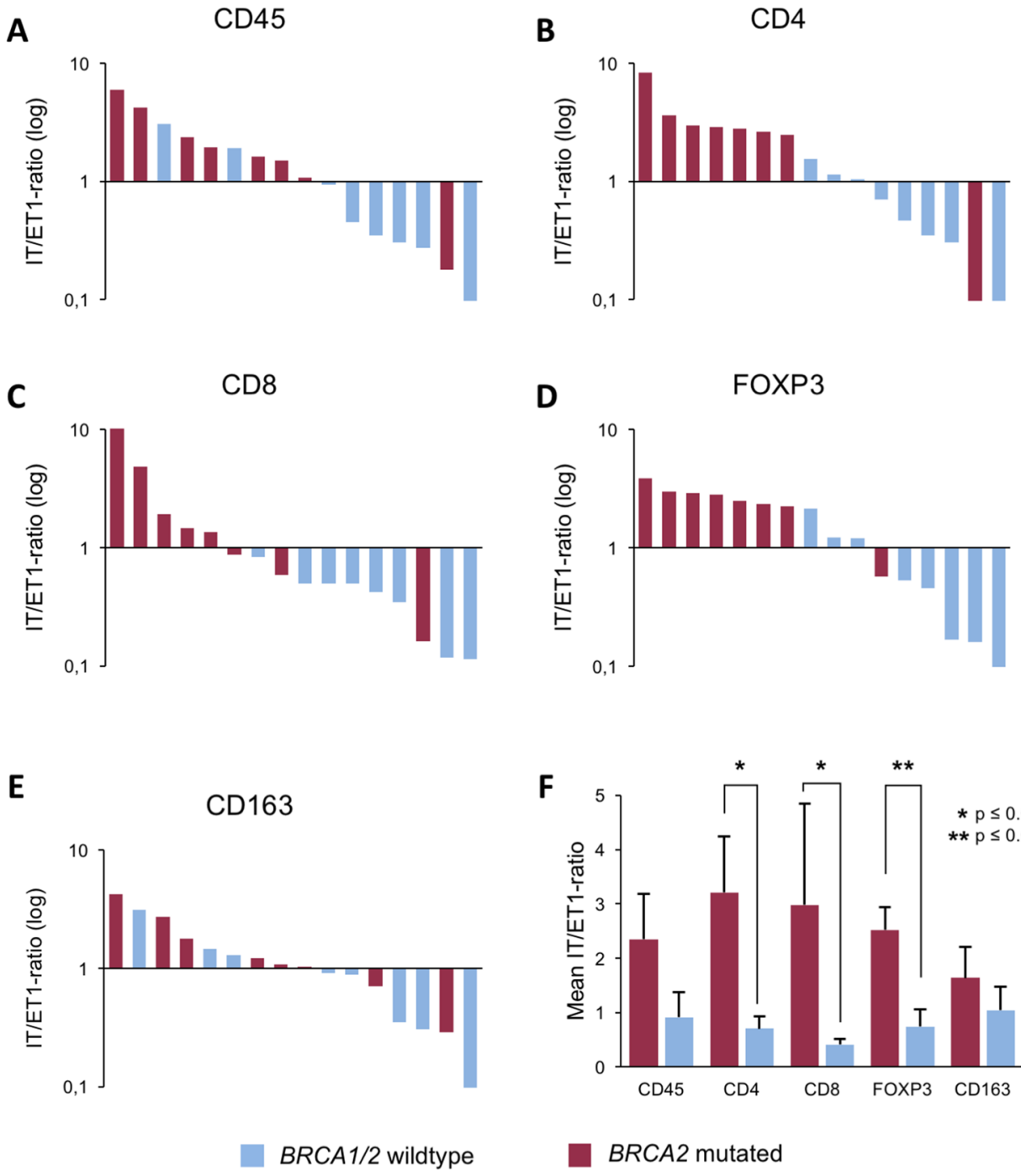

$B R C A 1 / 2$ wildtype

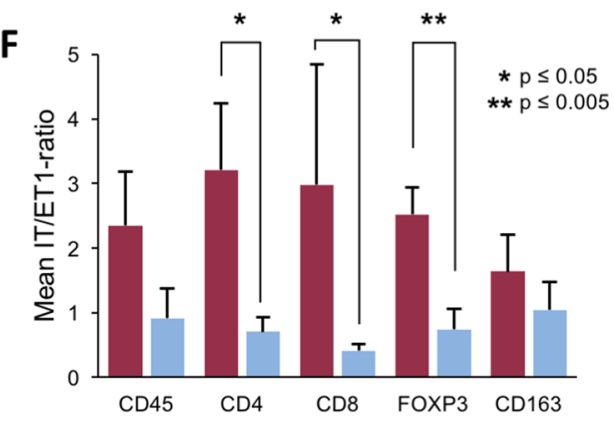

BRCA2 mutated 
$B R C A 2$-mutated compared to BRCA1/2 wild-type tumors, we calculated the CD8/FOXP3 ratio for each patient and each group. BRCA2-mutated tumors showed a trend towards lower CD8/FOXP3 ratios (Fig. 6), suggesting that they have more FOXP3-positive T cells in comparison with CD8 positive $\mathrm{T}$ cells, although the mean ratios of both groups were not significantly different ( 2.73 vs. $4.53, p=0.12$ ).

Taken together, these findings suggest differences not only in the IT and ET distribution of immune cells in $B R C A 2$-mutated and wild-type prostate cancers, but also in the composition of TIL populations.

\section{Immune phenotype in prostate cancer biopsies}

To confirm and extend our results, we next analyzed seven patients from which prostate cancer biopsies had been obtained and sequenced using a 37 gene panel (Fig. 7). One patient had a deleterious mutations in BRCA2 (p.Glu2981fs*7, allele frequency $57.9 \%$ ), two patients had a deleterious mutation in ATM (p.Arg2993*, allele frequency $40.2 \%$; and p.Ser470*, allele frequency $40.4 \%$ ), and four patients were wild-type for $B R C A 2$ and $A T M$ and did not show any deleterious point mutations in any of the other 37 genes tested.

Because of the small size of prostate biopsies, analyses were limited to two areas, i.e., the intratumoral (IT) and extratumoral (ET) compartment after FFPE sections were stained for CD45, CD8, FOXP3, and CD163. The presence of a deleterious $B R C A 2$ mutation was found to correlate with a significantly higher number of intratumoral CD8 positive T lymphocytes (14.6-fold, $p=0.01$, Fig. 7b). Remarkably, tumors with a deleterious mutation in ATM did not show more CD8 positive lymphocytes in the IT area, but more CD163 positive macrophages instead without reaching statistical significance. One ATM-mutated prostate cancer

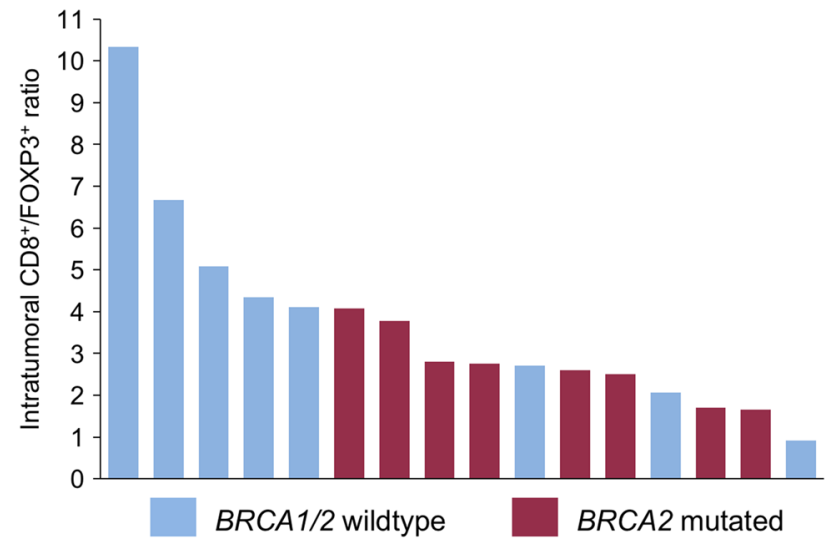

Fig. 6 Intratumoral CD8/FOXP3 ratio is reduced in BRCA2-mutated tumors. Waterfall plot of intratumoral CD8/FOXP3 ratios in $B R C A 1 / 2$ wild-type (blue) and $B R C A 2$-mutated (red) prostate cancer had a significantly higher frequency of extratumoral CD45 positive lymphocytes. The frequency of FOXP3-positive lymphocytes was overall low in tumors with a $B R C A 2$ or ATM mutation.

These results underscore that mutations in BRCA2 shape the immune microenvironment, which can be detected even in prostate cancer biopsies.

\section{Discussion}

The primary goal of this proof-of-concept study was to better understand the impact of the BRCAl/2 mutation status on the immune phenotype of prostate cancer.

Our results show that BRCA2-mutated tumors harbor an enhanced intratumoral immune infiltrate compared to BRCA1/2 wild-type tumors, in particular with respect to $\mathrm{T}$ lymphocytes expressing CD4, CD8, and FOXP3. Of note, there was a trend towards a lower intratumoral $\mathrm{CD} 8^{+}$to $\mathrm{FOXP}^{+}$ratio in $B R C A 2$-mutated tumors that needs to be carefully interpreted, but suggests a more suppressed tumor immune microenvironment.

$B R C A 2$ mutations have been found to be associated with an increased mutational load [6-8], neoepitope formation [10], increased tumor-infiltrating lymphocytes [10], and a favorable response to immune checkpoint blockade [7, 25, 26]. However, the use of immune checkpoint inhibitors in advanced prostate cancer has been largely unsuccessful with respect to an improvement of overall patient survival thus far. Although a positive response to this treatment modality occurs frequently in patients with high intratumoral CD4and CD8-positive T lymphocytes ("inflamed" tumors), their presence is clearly not sufficient for a response. The latter is also modulated by cells associated with immune suppression/immune homeostasis such as FOXP3-positive regulatory T cells, CD163-positive tumor-associated (M2) macrophages, or myeloid-derived suppressor cells (MDSCs). Hence, the presence of intratumoral $\mathrm{T}$ lymphocytes is necessary but clearly not sufficient for a response to immune checkpoint inhibitors [52], which makes treatment responses in BRCA2-mutated prostate cancer difficult to predict. Moreover, it is critical that cytotoxic T lymphocytes are capable of killing tumor cells, i.e., are not exhausted or dysfunctional. Recent approaches to target regulatory $\mathrm{T}$ cells may hence represent promising strategies to prime prostate cancer for immune checkpoint blockade [53, 54].

A subgroup analysis in the KEYNOTE-199 trial showed an increased, but still moderate ORR of $12 \%$ in BRCA1/2mutated mCRPC [25] in response to pembrolizumab. DNAdamaging agents such as platinum salts or PARP inhibitors [55] may also increase the mutational load, the number of neoepitopes [56], and, therefore, possibly the response rate to immune checkpoint inhibitors and other immunotherapies. 


\section{CD45}

A

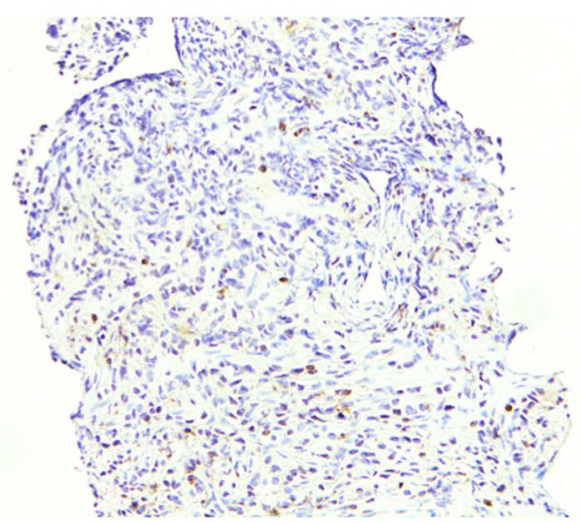

IT
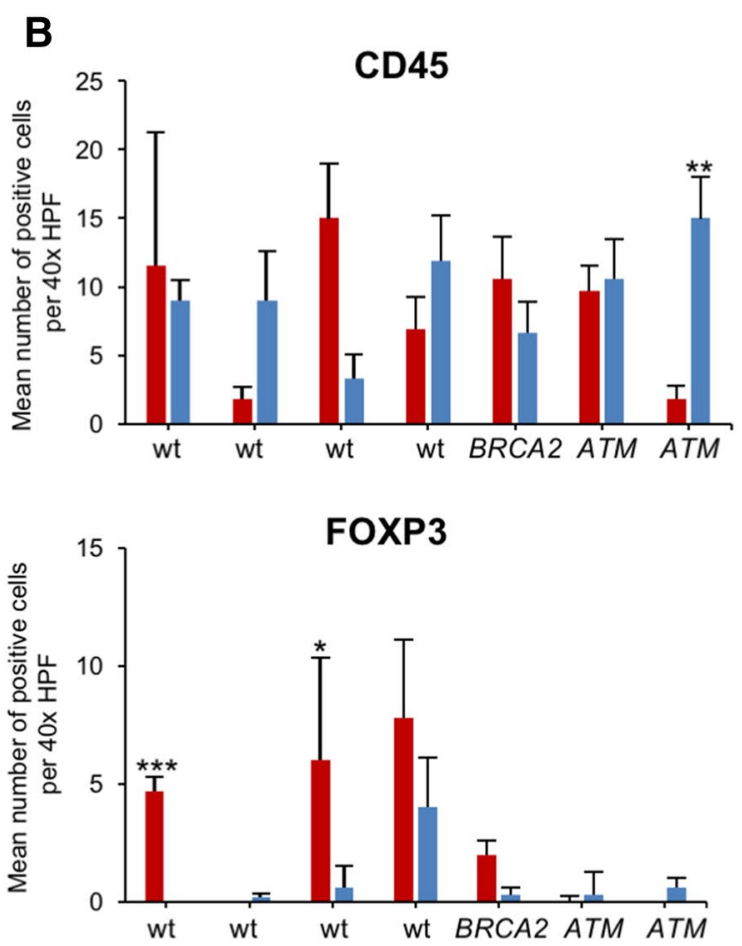

IT

Fig. 7 Immune phenotype of prostate cancer biopsies from BRCA2or ATM-mutated tumors. a Representative immunohistochemical staining of prostate cancer biopsies for CD45 showing the intratumoral (IT) area (left) and an IT area with adjacent extratumoral (ET) area (right). The scale bar represents $250 \mu \mathrm{m}$. b Bar graphs show the mean number of positive cells per $40 \times \mathrm{HPF}$ in BRCA2-mutated or

Results from ongoing studies focusing on combinations of PD1/PD-L1 antibodies with PARP inhibitors including nivolumab/rucaparib (CheckMate 9KD, NCT03338790), pembrolizumab/olaparib (KEYNOTE-365, NCT02861573), and durvalumab/olaparib (NCT02484404) [57] are, therefore, urgently awaited.

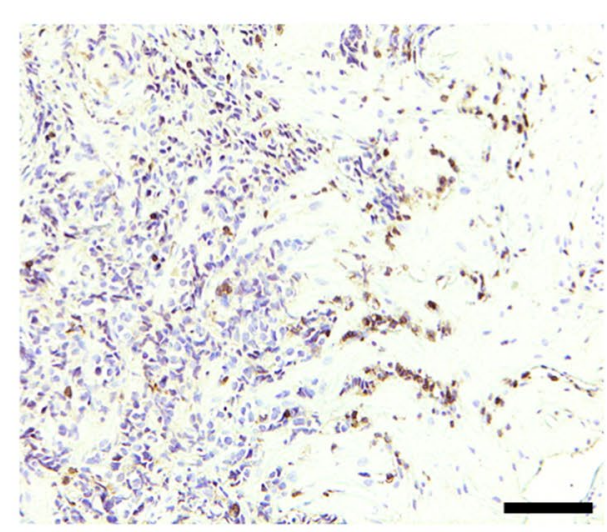

ET
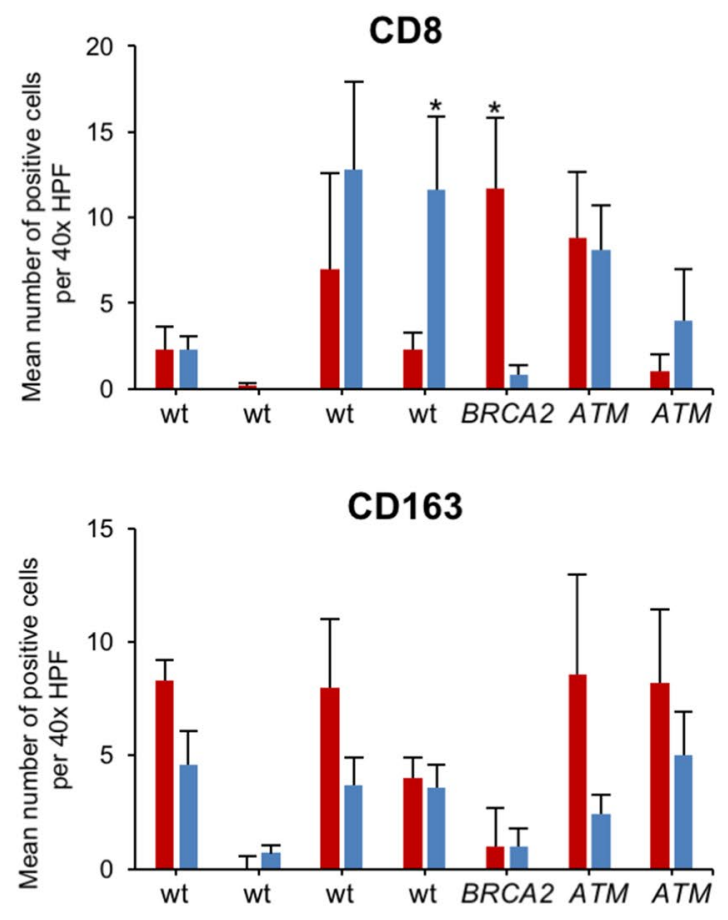

ET

ATM-mutated biopsies compared to wild-type (wt) specimens in the intratumoral (IT) and extratumoral (ET) compartments for CD45, CD8, FOXP3, and CD163. Each bar represents counts from a mean of six $40 \times$ HPFs. Standard errors are shown. $* p \leq 0.05, * * p \leq 0.005$, $* * * p \leq 0.0005$

The reason for the relatively small difference in the number of TCR clones between BRCA2-mutated and wildtype tumors found in this study in comparison with the staining results is unclear. We attribute this result primarily to methodological differences, since no microdissection of tumor and stroma was performed prior to TCR 
sequencing. While other factors such as RNA degradation cannot be excluded, our finding showing the pronounced differences between intra- and extratumoral compartments in terms of lymphocyte infiltration dependent on the genetic background strongly argues for a tumor cell enrichment in future TCR sequencing studies in prostate cancer.

Limitations of our study are the small sample size, the focus on BRCA2 and ATM mutations, the lack of tumor mutational burden measurements, and that no MDSCs were analyzed.

Collectively, our results underscore that the $B R C A 2$ mutation status shapes the immune phenotype of prostate cancer with an increase of intratumoral immune cells that may in part be immunosuppressive. Future strategies to prime prostate cancer for immune checkpoint therapy may hence not only focus on increasing the mutational burden, but also on manipulating immunosuppressive cell populations $[54,58]$.

Acknowledgements We are grateful to the tissue bank of the National Center for Tumor Diseases (NCT) Heidelberg for tissue procurement.

Author contributions $\mathrm{MJ}, \mathrm{PK}, \mathrm{MH}, \mathrm{CG}, \mathrm{AS}$, and $\mathrm{SD}$ conceived and designed the project. PK, MJ, VE, MK, JH, SM, BK, and AK performed experiments. JL, FS, and A-LV assisted with experiments. MJ, $\mathrm{PK}, \mathrm{CN}, \mathrm{JH}, \mathrm{SM}, \mathrm{BK}$, and SD analyzed data. CN, SZ, DJ, MH, and CG recruited patients and contributed important patient information. HS, $\mathrm{AD}$, and PS gave important advice for data interpretation. MJ, PK, and SD prepared the figures and wrote the manuscript. All authors read and commented on the manuscript.

Funding This work was supported by the Medical Faculty of the University of Heidelberg School of Medicine.

\section{Compliance with ethical standards}

Conflict of interest The authors declare that they have no potential conflict of interest.

Ethical standards All tissue-based experiments in this study were in accordance with the regulations of the tissue bank and with the approval of the ethics committee of the University of Heidelberg School of Medicine (206/2005, 207/2005, S-085/2012). Targeted next-generation sequencing was performed under the approval of the ethics committee of the University of Heidelberg School of Medicine (S-051/2017).

Informed consent Patients provided written informed consent for the use of their tissue specimens and clinical data for research and publication prior to undergoing radical prostatectomy at the Department of Urology of the University of Heidelberg. Patients that were part of the targeted NGS panel cohort provided written informed consent for the use of tissue specimens and clinical data for research and publication prior to prostate biopsy and, in addition, written informed consent for participation in the prospective study registered under registration number DRKS00015159 in the German Clinical Trials Register (DRKS), an approved primary register of the WHO fulfilling the requirements of the International Committee of Medical Journal Editors (ICMJE).
Open Access This article is distributed under the terms of the Creative Commons Attribution 4.0 International License (http://creativeco mmons.org/licenses/by/4.0/), which permits unrestricted use, distribution, and reproduction in any medium, provided you give appropriate credit to the original author(s) and the source, provide a link to the Creative Commons license, and indicate if changes were made.

\section{References}

1. Ferlay J, Steliarova-Foucher E, Lortet-Tieulent J, Rosso S, Coebergh JW, Comber H, Forman D, Bray F (2013) Cancer incidence and mortality patterns in Europe: estimates for 40 countries in 2012. Eur J Cancer 49(6):1374-1403. https://doi.org/10.1016/j. ejca.2012.12.027

2. Siegel RL, Miller KD, Jemal A (2018) Cancer statistics. CA Cancer J Clin 68(1):7-30. https://doi.org/10.3322/caac.21442

3. Pritchard CC, Mateo J, Walsh MF, De Sarkar N, Abida W, Beltran H, Garofalo A, Gulati R, Carreira S, Eeles R, Elemento O, Rubin MA, Robinson D, Lonigro R, Hussain M, Chinnaiyan A, Vinson J, Filipenko J, Garraway L, Taplin ME, AlDubayan S, Han GC, Beightol M, Morrissey C, Nghiem B, Cheng HH, Montgomery B, Walsh T, Casadei S, Berger M, Zhang L, Zehir A, Vijai J, Scher HI, Sawyers C, Schultz N, Kantoff PW, Solit D, Robson M, Van Allen EM, Offit K, de Bono J, Nelson PS (2016) Inherited DNArepair gene mutations in men with metastatic prostate cancer. N Engl J Med 375(5):443-453. https://doi.org/10.1056/NEJMo a1603144

4. Hall JM, Lee MK, Newman B, Morrow JE, Anderson LA, Huey B, King MC (1990) Linkage of early-onset familial breast cancer to chromosome 17q21. Science 250(4988):1684-1689

5. Wooster R, Neuhausen SL, Mangion J, Quirk Y, Ford D, Collins N, Nguyen K, Seal S, Tran T, Averill D et al (1994) Localization of a breast cancer susceptibility gene, BRCA2, to chromosome 13q12-13. Science 265(5181):2088-2090

6. Nik-Zainal S, Van Loo P, Wedge DC, Alexandrov LB, Greenman CD, Lau KW, Raine K, Jones D, Marshall J, Ramakrishna M, Shlien A, Cooke SL, Hinton J, Menzies A, Stebbings LA, Leroy C, Jia M, Rance R, Mudie LJ, Gamble SJ, Stephens PJ, McLaren S, Tarpey PS, Papaemmanuil E, Davies HR, Varela I, McBride DJ, Bignell GR, Leung K, Butler AP, Teague JW, Martin S, Jonsson G, Mariani O, Boyault S, Miron P, Fatima A, Langerod A, Aparicio SA, Tutt A, Sieuwerts AM, Borg A, Thomas G, Salomon AV, Richardson AL, Borresen-Dale AL, Futreal PA, Stratton MR, Campbell PJ, Breast Cancer Working Group of the International Cancer Genome Consortium (2012) The life history of 21 breast cancers. Cell 149(5):994-1007. https://doi.org/10.1016/j. cell.2012.04.023

7. Rizvi NA, Hellmann MD, Snyder A, Kvistborg P, Makarov V, Havel JJ, Lee W, Yuan J, Wong P, Ho TS, Miller ML, Rekhtman N, Moreira AL, Ibrahim F, Bruggeman C, Gasmi B, Zappasodi R, Maeda Y, Sander C, Garon EB, Merghoub T, Wolchok JD, Schumacher TN, Chan TA (2015) Cancer immunology. Mutational landscape determines sensitivity to PD-1 blockade in nonsmall cell lung cancer. Science 348(6230):124-128. https://doi. org/10.1126/science.aaa1348

8. Budczies J, Bockmayr M, Denkert C, Klauschen F, Lennerz JK, Gyorffy B, Dietel M, Loibl S, Weichert W, Stenzinger A (2015) Classical pathology and mutational load of breast cancer - integration of two worlds. J Pathol Clin Res 1(4):225-238. https://doi. org/10.1002/cjp2.25

9. Castro E, Jugurnauth-Little S, Karlsson Q, Al-Shahrour F, Pineiro-Yanez E, Van de Poll F, Leongamornlert D, Dadaev T, Govindasami K, Guy M, Eeles R, Kote-Jarai Z, Ukgpcs E, Studies I (2015) High burden of copy number alterations and c-MYC 
amplification in prostate cancer from BRCA2 germline mutation carriers. Ann Oncol 26(11):2293-2300. https://doi.org/10.1093/ annonc/mdv356

10. Strickland KC, Howitt BE, Shukla SA, Rodig S, Ritterhouse LL, Liu JF, Garber JE, Chowdhury D, Wu CJ, D'Andrea AD, Matulonis UA, Konstantinopoulos PA (2016) Association and prognostic significance of BRCA1/2-mutation status with neoantigen load, number of tumor-infiltrating lymphocytes and expression of PD-1/PD-L1 in high grade serous ovarian cancer. Oncotarget 7(12):13587-13598. https://doi.org/10.18632/oncotarget.7277

11. Cheng HH, Pritchard CC, Boyd T, Nelson PS, Montgomery B (2016) Biallelic inactivation of BRCA2 in platinum-sensitive metastatic castration-resistant prostate cancer. Eur Urol 69(6):992995. https://doi.org/10.1016/j.eururo.2015.11.022

12. Clarke N, Wiechno P, Alekseev B, Sala N, Jones R, Kocak I, Chiuri VE, Jassem J, Flechon A, Redfern C, Goessl C, Burgents J, Kozarski R, Hodgson D, Learoyd M, Saad F (2018) Olaparib combined with abiraterone in patients with metastatic castrationresistant prostate cancer: a randomised, double-blind, placebocontrolled, phase 2 trial. Lancet Oncol. https://doi.org/10.1016/ S1470-2045(18)30365-6

13. Mateo J, Carreira S, Sandhu S, Miranda S, Mossop H, PerezLopez R, Nava Rodrigues D, Robinson D, Omlin A, Tunariu N, Boysen G, Porta N, Flohr P, Gillman A, Figueiredo I, Paulding C, Seed G, Jain S, Ralph C, Protheroe A, Hussain S, Jones R, Elliott T, McGovern U, Bianchini D, Goodall J, Zafeiriou Z, Williamson CT, Ferraldeschi R, Riisnaes R, Ebbs B, Fowler G, Roda D, Yuan W, Wu YM, Cao X, Brough R, Pemberton H, A'Hern R, Swain A, Kunju LP, Eeles R, Attard G, Lord CJ, Ashworth A, Rubin MA, Knudsen KE, Feng FY, Chinnaiyan AM, Hall E, de Bono JS (2015) DNA-repair defects and olaparib in metastatic prostate cancer. N Engl J Med 373(18):1697-1708. https://doi. org/10.1056/NEJMoa1506859

14. Nientiedt C, Tolstov Y, Volckmar AL, Endris V, Bonekamp D, Haberkorn U, Jager D, Sultmann H, Stenzinger A, Hohenfellner M, Grullich C, Duensing S (2017) PARP inhibition in BRCA2mutated prostate cancer. Ann Oncol 28(1):189-191. https://doi. org/10.1093/annonc/mdw445

15. Ashworth A, Lord CJ (2018) Synthetic lethal therapies for cancer: what's next after PARP inhibitors? Nat Rev Clin Oncol 15(9):564-576. https://doi.org/10.1038/s41571-018-0055-6

16. Nientiedt C, Heller M, Endris V, Volckmar AL, Zschabitz S, Tapia-Laliena MA, Duensing A, Jager D, Schirmacher P, Sultmann H, Stenzinger A, Hohenfellner M, Grullich C, Duensing $S$ (2017) Mutations in BRCA2 and taxane resistance in prostate cancer. Sci Rep 7(1):4574. https://doi.org/10.1038/s41598-01704897-x

17. Dallos MC, Drake CG (2018) Blocking PD-1/PD-L1 in genitourinary malignancies: to immunity and beyond. Cancer J 24(1):20 30. https://doi.org/10.1097/PPO.0000000000000302

18. Balar AV, Weber JS (2017) PD-1 and PD-L1 antibodies in cancer: current status and future directions. Cancer Immunol Immunother 66(5):551-564. https://doi.org/10.1007/s00262-017-1954-6

19. McGranahan N, Furness AJ, Rosenthal R, Ramskov S, Lyngaa R, Saini SK, Jamal-Hanjani M, Wilson GA, Birkbak NJ, Hiley CT, Watkins TB, Shafi S, Murugaesu N, Mitter R, Akarca AU, Linares J, Marafioti T, Henry JY, Van Allen EM, Miao D, Schilling B, Schadendorf D, Garraway LA, Makarov V, Rizvi NA, Snyder A, Hellmann MD, Merghoub T, Wolchok JD, Shukla SA, Wu CJ, Peggs KS, Chan TA, Hadrup SR, Quezada SA, Swanton C (2016) Clonal neoantigens elicit $\mathrm{T}$ cell immunoreactivity and sensitivity to immune checkpoint blockade. Science 351(6280):1463-1469. https://doi.org/10.1126/science.aaf1490

20. Lawrence MS, Stojanov P, Polak P, Kryukov GV, Cibulskis K, Sivachenko A, Carter SL, Stewart C, Mermel CH, Roberts SA, Kiezun A, Hammerman PS, McKenna A, Drier Y, Zou L, Ramos
AH, Pugh TJ, Stransky N, Helman E, Kim J, Sougnez C, Ambrogio L, Nickerson E, Shefler E, Cortes ML, Auclair D, Saksena G, Voet D, Noble M, DiCara D, Lin P, Lichtenstein L, Heiman DI, Fennell T, Imielinski M, Hernandez B, Hodis E, Baca S, Dulak AM, Lohr J, Landau DA, Wu CJ, Melendez-Zajgla J, HidalgoMiranda A, Koren A, McCarroll SA, Mora J, Crompton B, Onofrio R, Parkin M, Winckler W, Ardlie K, Gabriel SB, Roberts CWM, Biegel JA, Stegmaier K, Bass AJ, Garraway LA, Meyerson M, Golub TR, Gordenin DA, Sunyaev S, Lander ES, Getz G (2013) Mutational heterogeneity in cancer and the search for new cancer-associated genes. Nature 499(7457):214-218. https://doi. org/10.1038/nature12213

21. Cancer Genome Atlas Research N (2015) The molecular taxonomy of primary prostate cancer. Cell 163(4):1011-1025. https:// doi.org/10.1016/j.cell.2015.10.025

22. Beer TM, Kwon ED, Drake CG, Fizazi K, Logothetis C, Gravis G, Ganju V, Polikoff J, Saad F, Humanski P, Piulats JM, Gonzalez Mella P, Ng SS, Jaeger D, Parnis FX, Franke FA, Puente J, Carvajal R, Sengelov L, McHenry MB, Varma A, van den Eertwegh AJ, Gerritsen W (2017) Randomized, double-blind, phase III trial of ipilimumab versus placebo in asymptomatic or minimally symptomatic patients with metastatic chemotherapy-naive castrationresistant prostate cancer. J Clin Oncol 35(1):40-47. https://doi. org/10.1200/JCO.2016.69.1584

23. Kwon ED, Drake CG, Scher HI, Fizazi K, Bossi A, van den Eertwegh AJ, Krainer M, Houede N, Santos R, Mahammedi H, Ng S, Maio M, Franke FA, Sundar S, Agarwal N, Bergman AM, Ciuleanu TE, Korbenfeld E, Sengelov L, Hansen S, Logothetis C, Beer TM, McHenry MB, Gagnier P, Liu D, Gerritsen WR, Investigators CA (2014) Ipilimumab versus placebo after radiotherapy in patients with metastatic castration-resistant prostate cancer that had progressed after docetaxel chemotherapy (CA184-043): a multicentre, randomised, double-blind, phase 3 trial. Lancet Oncol 15(7):700-712. https://doi.org/10.1016/S1470-2045(14)70189-5

24. Topalian SL, Hodi FS, Brahmer JR, Gettinger SN, Smith DC, McDermott DF, Powderly JD, Carvajal RD, Sosman JA, Atkins MB, Leming PD, Spigel DR, Antonia SJ, Horn L, Drake CG, Pardoll DM, Chen L, Sharfman WH, Anders RA, Taube JM, McMiller TL, Xu H, Korman AJ, Jure-Kunkel M, Agrawal S, McDonald D, Kollia GD, Gupta A, Wigginton JM, Sznol M (2012) Safety, activity, and immune correlates of anti-PD-1 antibody in cancer. N Engl J Med 366(26):2443-2454. https://doi. org/10.1056/NEJMoa1200690

25. De Bono JS, Ojamaa K, Rodriguez JMP, Drake CG, Hoimes CJ, Wu H, Poehlein CH, Antonarakis ES (2018) KEYNOTE-199: pembrolizumab (pembro) for docetaxel-refractory metastatic castration-resistant prostate cancer (mCRPC). J Clin Oncol 36:(suppl; abstr 5007)

26. Hugo W, Zaretsky JM, Sun L, Song C, Moreno BH, Hu-Lieskovan S, Berent-Maoz B, Pang J, Chmielowski B, Cherry G, Seja E, Lomeli S, Kong X, Kelley MC, Sosman JA, Johnson DB, Ribas A, Lo RS (2016) Genomic and transcriptomic features of response to anti-PD-1 therapy in metastatic melanoma. Cell 165(1):35-44. https://doi.org/10.1016/j.cell.2016.02.065

27. Valdman A, Jaraj SJ, Comperat E, Charlotte F, Roupret M, Pisa P, Egevad L (2010) Distribution of Foxp3-, CD4- and CD8-positive lymphocytic cells in benign and malignant prostate tissue. APMIS 118(5):360-365. https://doi.org/10.1111/j.1600-0463.2010.02604 .x

28. Strasner A, Karin M (2015) Immune infiltration and prostate cancer. Front Oncol 5:128. https://doi.org/10.3389/fonc.2015.00128

29. Mercader M, Bodner BK, Moser MT, Kwon PS, Park ES, Manecke RG, Ellis TM, Wojcik EM, Yang D, Flanigan RC, Waters WB, Kast WM, Kwon ED (2001) T cell infiltration of the prostate induced by androgen withdrawal in patients with prostate 
cancer. Proc Natl Acad Sci USA 98(25):14565-14570. https://doi. org/10.1073/pnas.251140998

30. Sorrentino C, Musiani P, Pompa P, Cipollone G, Di Carlo E (2011) Androgen deprivation boosts prostatic infiltration of cytotoxic and regulatory $\mathrm{T}$ lymphocytes and has no effect on disease-free survival in prostate cancer patients. Clin Cancer Res 17(6):15711581. https://doi.org/10.1158/1078-0432.CCR-10-2804

31. Bishop JL, Sio A, Angeles A, Roberts ME, Azad AA, Chi KN, Zoubeidi A (2015) PD-L1 is highly expressed in Enzalutamide resistant prostate cancer. Oncotarget 6(1):234-242. https://doi. org/10.18632/oncotarget.2703

32. Ness N, Andersen S, Valkov A, Nordby Y, Donnem T, Al-Saad S, Busund LT, Bremnes RM, Richardsen E (2014) Infiltration of $\mathrm{CD}^{+}$lymphocytes is an independent prognostic factor of biochemical failure-free survival in prostate cancer. Prostate 74(14):1452-1461. https://doi.org/10.1002/pros.22862

33. Petitprez F, Fossati N, Vano Y, Freschi M, Becht E, Luciano R, Calderaro J, Guedet T, Lacroix L, Rancoita PMV, Montorsi F, Fridman WH, Sautes-Fridman C, Briganti A, Doglioni C, Bellone M (2019) PD-L1 expression and CD8(+) T-cell infiltrate are associated with clinical progression in patients with nodepositive prostate cancer. Eur Urol Focus 5(2):192-196. https:// doi.org/10.1016/j.euf.2017.05.013

34. McArdle PA, Canna K, McMillan DC, McNicol AM, Campbell R, Underwood MA (2004) The relationship between T-lymphocyte subset infiltration and survival in patients with prostate cancer. $\mathrm{Br}$ J Cancer 91(3):541-543. https://doi.org/10.1038/sj.bjc.6601943

35. Davidsson S, Ohlson AL, Andersson SO, Fall K, Meisner A, Fiorentino M, Andren O, Rider JR (2013) CD4 helper T cells, CD8 cytotoxic T cells, and FOXP3(+) regulatory T cells with respect to lethal prostate cancer. Mod Pathol 26(3):448-455. https ://doi.org/10.1038/modpathol.2012.164

36. Leclerc BG, Charlebois R, Chouinard G, Allard B, Pommey S, Saad F, Stagg J (2016) CD73 expression is an independent prognostic factor in prostate cancer. Clin Cancer Res 22(1):158-166. https://doi.org/10.1158/1078-0432.CCR-15-1181

37. Lundholm M, Hagglof C, Wikberg ML, Stattin P, Egevad L, Bergh A, Wikstrom P, Palmqvist R, Edin S (2015) Secreted factors from colorectal and prostate cancer cells skew the immune response in opposite directions. Sci Rep 5:15651. https://doi.org/10.1038/ srep15651

38. Nolan E, Savas P, Policheni AN, Darcy PK, Vaillant F, Mintoff CP, Dushyanthen S, Mansour M, Pang JB, Fox SB, Kathleen Cuningham Foundation Consortium for Research into Familial Breast Consortium, Perou CM, Visvader JE, Gray DHD, Loi S, Lindeman GJ (2017) Combined immune checkpoint blockade as a therapeutic strategy for BRCA1-mutated breast cancer. Sci Transl Med. https://doi.org/10.1126/scitranslmed.aal4922

39. Wen WX, Leong CO (2019) Association of BRCA1- and BRCA2deficiency with mutation burden, expression of PD-L1/PD-1, immune infiltrates, and $\mathrm{T}$ cell-inflamed signature in breast cancer. PLoS One 14(4):e0215381. https://doi.org/10.1371/journ al.pone. 0215381

40. Soslow RA, Han G, Park KJ, Garg K, Olvera N, Spriggs DR, Kauff ND, Levine DA (2012) Morphologic patterns associated with BRCA1 and BRCA2 genotype in ovarian carcinoma. Mod Pathol 25(4):625-636. https://doi.org/10.1038/modpa thol.2011.183

41. Endris V, Penzel R, Warth A, Muckenhuber A, Schirmacher P, Stenzinger A, Weichert W (2013) Molecular diagnostic profiling of lung cancer specimens with a semiconductor-based massive parallel sequencing approach: feasibility, costs, and performance compared with conventional sequencing. J Mol Diagn 15(6):765775. https://doi.org/10.1016/j.jmoldx.2013.06.002

42. Jesinghaus M, Pfarr N, Endris V, Kloor M, Volckmar AL, Brandt R, Herpel E, Muckenhuber A, Lasitschka F, Schirmacher P,
Penzel R, Weichert W, Stenzinger A (2016) Genotyping of colorectal cancer for cancer precision medicine: results from the IPH Center for Molecular Pathology. Genes Chromosomes Cancer 55(6):505-521. https://doi.org/10.1002/gcc.22352

43. Robinson JT, Thorvaldsdottir H, Winckler W, Guttman M, Lander ES, Getz G, Mesirov JP (2011) Integrative genomics viewer. Nat Biotechnol 29(1):24-26. https://doi.org/10.1038/nbt.1754

44. Wang K, Li M, Hakonarson H (2010) ANNOVAR: functional annotation of genetic variants from high-throughput sequencing data. Nucleic Acids Res 38(16):e164. https://doi.org/10.1093/ nar/gkq603

45. Gerdes J, Schwab U, Lemke H, Stein H (1983) Production of a mouse monoclonal antibody reactive with a human nuclear antigen associated with cell proliferation. Int J Cancer 31(1):13-20

46. Grant J, Bourcier K, Wallace S, Pan D, Conway A, Seyfert-Margolis V, Wallace PK (2009) Validated protocol for FoxP3 reveals increased expression in type 1 diabetes patients. Cytom B Clin Cytom 76(2):69-78. https://doi.org/10.1002/cyto.b.20446

47. Hogger P, Dreier J, Droste A, Buck F, Sorg C (1998) Identification of the integral membrane protein RM3/1 on human monocytes as a glucocorticoid-inducible member of the scavenger receptor cysteine-rich family (CD163). J Immunol 161(4):1883-1890

48. Kurtin PJ, Pinkus GS (1985) Leukocyte common antigen-a diagnostic discriminant between hematopoietic and nonhematopoietic neoplasms in paraffin sections using monoclonal antibodies: correlation with immunologic studies and ultrastructural localization. Hum Pathol 16(4):353-365

49. Matsuda I, Sugihara N, Yunokizaki H, Abe T, Hirota S (2015) A case of immunohistochemical false positive staining caused by incompatibility between a CD4 antibody and an autostainer. Int J Clin Exp Pathol 8(1):1019-1024

50. Parra ER, Uraoka N, Jiang M, Cook P, Gibbons D, Forget MA, Bernatchez C, Haymaker C, Wistuba II, Rodriguez-Canales J (2017) Validation of multiplex immunofluorescence panels using multispectral microscopy for immune-profiling of formalin-fixed and paraffin-embedded human tumor tissues. Sci Rep 7(1):13380. https://doi.org/10.1038/s41598-017-13942-8

51. Schats KA, Van Vre EA, De Schepper S, Boeckx C, Schrijvers DM, Waelput W, Fransen E, Vanden Bempt I, Neyns B, De Meester I, Kockx MM (2017) Validated programmed cell death ligand 1 immunohistochemistry assays (E1L3 N and SP142) reveal similar immune cell staining patterns in melanoma when using the same sensitive detection system. Histopathology 70(2):253-263. https://doi.org/10.1111/his.13056

52. Chen DS, Mellman I (2017) Elements of cancer immunity and the cancer-immune set point. Nature 541(7637):321-330. https://doi. org/10.1038/nature21349

53. Kiniwa Y, Miyahara Y, Wang HY, Peng W, Peng G, Wheeler TM, Thompson TC, Old LJ, Wang RF (2007) CD8 ${ }^{+}$Foxp $3^{+}$regulatory $\mathrm{T}$ cells mediate immunosuppression in prostate cancer. Clin Cancer Res 13(23):6947-6958. https://doi.org/10.1158/1078-0432. CCR-07-0842

54. Di Pilato M, Kim EY, Cadilha BL, Prussmann JN, Nasrallah MN, Seruggia D, Usmani SM, Misale S, Zappulli V, Carrizosa E, Mani V, Ligorio M, Warner RD, Medoff BD, Marangoni F, Villani AC, Mempel TR (2019) Targeting the CBM complex causes Treg cells to prime tumours for immune checkpoint therapy. Nature. https:// doi.org/10.1038/s41586-019-1215-2

55. Farmer H, McCabe N, Lord CJ, Tutt AN, Johnson DA, Richardson TB, Santarosa M, Dillon KJ, Hickson I, Knights C, Martin NM, Jackson SP, Smith GC, Ashworth A (2005) Targeting the DNA repair defect in BRCA mutant cells as a therapeutic strategy. Nature 434(7035):917-921. https://doi.org/10.1038/nature03445

56. Jackaman C, Majewski D, Fox SA, Nowak AK, Nelson DJ (2012) Chemotherapy broadens the range of tumor antigens seen by 
cytotoxic CD8(+) T cells in vivo. Cancer Immunol Immunother 61(12):2343-2356. https://doi.org/10.1007/s00262-012-1307-4

57. Karzai F, Madan RA, Owens H, Hankin A, Couvillon A, Cordes LM, Fakhrejahani F, Houston ND, Trepel JB, Chen C, Edelman DC, Meltzer PS, Steinberg SM, Gulley JL, Dahut WL, Lee $\mathrm{J}-\mathrm{m}$ (2017) Combination of PDL-1 and PARP inhibition in an unselected population with metastatic castrate-resistant prostate cancer (mCRPC). J Clin Oncol 35(15_suppl):5026. https://doi. org/10.1200/jco.2017.35.15_suppl.5026
58. Lu X, Horner JW, Paul E, Shang X, Troncoso P, Deng P, Jiang S, Chang Q, Spring DJ, Sharma P, Zebala JA, Maeda DY, Wang YA, DePinho RA (2017) Effective combinatorial immunotherapy for castration-resistant prostate cancer. Nature 543(7647):728-732. https://doi.org/10.1038/nature21676

Publisher's Note Springer Nature remains neutral with regard to jurisdictional claims in published maps and institutional affiliations.

\section{Affiliations}

\section{Maximilian Jenzer ${ }^{1,2} \cdot$ Peter Keß ${ }^{1} \cdot$ Cathleen Nientiedt $^{1,2} \cdot$ Volker Endris $^{3} \cdot$ Maximilian Kippenberger $^{1}$. Jonas Leichsenring ${ }^{3}$ - Fabian Stögbauer ${ }^{3}$. Josh Haimes ${ }^{4}$. Skyler Mishkin ${ }^{4}$ - Brian Kudlow ${ }^{4}$. Adam Kaczorowski ${ }^{1}$. Stefanie Zschäbitz, ${ }^{1,2}$ Anna-Lena Volckmar ${ }^{3}$. Holger Sültmann ${ }^{5,6} \cdot$ Dirk Jäger $^{2} \cdot$ Anette Duensing $^{7,8,9,10}$. Peter Schirmacher ${ }^{3} \cdot$ Markus Hohenfellner $^{10} \cdot$ Carsten Grüllich $^{2,11} \cdot$ Albrecht Stenzinger $^{3} \cdot$ Stefan Duensing $^{1,10} \mathbb{D}$}

1 Section of Molecular Urooncology, Department of Urology, University of Heidelberg School of Medicine, Im Neuenheimer Feld 517, 69120 Heidelberg, Germany

2 Department of Medical Oncology, University of Heidelberg School of Medicine, National Center for Tumor Diseases (NCT), Im Neuenheimer Feld 460, 69120 Heidelberg, Germany

3 Institute of Pathology, University of Heidelberg School of Medicine, Im Neuenheimer Feld 224, 69120 Heidelberg, Germany

4 ArcherDX, 2477 55th Street, Boulder, CO 80301, USA

5 National Center for Tumor Diseases, German Cancer Research Center, Cancer Genome Research, Im Neuenheimer Feld 460, 69120 Heidelberg, Germany

6 German Cancer Consortium (DKTK), Heidelberg, Germany

7 Cancer Therapeutics Program, UPMC Hillman Cancer Center, Pittsburgh, USA
8 Department of Pathology, University of Pittsburgh School of Medicine, 5117 Centre Avenue, Pittsburgh, PA 15213, USA

9 Section of Precision Oncology of Urological Malignancies, Department of Urology, University of Heidelberg School of Medicine, Im Neuenheimer Feld 517, 69120 Heidelberg, Germany

10 Department of Urology, University of Heidelberg School of Medicine, Im Neuenheimer Feld 110, 69120 Heidelberg, Germany

11 Section of Translational Urooncology, Department of Medical Oncology, University of Heidelberg School of Medicine, National Center for Tumor Diseases (NCT), Im Neuenheimer Feld 460, 69120 Heidelberg, Germany 